\title{
Analytical Expressions Pertaining to the Concentration of Substrates and Product in Phenol-Polyphenol Oxidase System Immobilized in Laponite Hydrogels: A Reciprocal Competitive Inhibition Process
}

\author{
K. Indira and L. Rajendran \\ Department of Mathematics, The Madura College, Madurai 625011, India \\ Correspondence should be addressed to L. Rajendran, raj_sms@rediffmail.com
}

Received 6 October 2011; Accepted 5 December 2011

Academic Editor: Marc Koper

Copyright (C) 2012 K. Indira and L. Rajendran. This is an open access article distributed under the Creative Commons Attribution License, which permits unrestricted use, distribution, and reproduction in any medium, provided the original work is properly cited.

\begin{abstract}
Theoretical analysis corresponding to the diffusion and kinetics of substrate and product in an amperometric biosensor is developed and reported in this paper. The nonlinear coupled system of diffusion equations was analytically solved by Homotopy perturbation method. Herein, we report the approximate analytical expressions pertaining to substrate concentration, product concentration, and current response for all possible values of diffusion and kinetic parameters. The numerical solution of this problem is also reported using Scilab/Matlab program. Also, we found excellent agreement between the analytical results and numerical results upon comparison.
\end{abstract}

\section{Introduction}

Theoretical modeling of biosensors usually provides some important insight into understanding the functioning of a biosensor. Usually, with the aid of an analytical device, it is not possible to measure the concentration of substrates inside the enzyme membranes. As a result, theoretical model in biosensors has been developed and employed as an important tool to study the analytical characteristics of biosensors. Initially, Goldman et al. [1] reported the theoretical modeling on biosensor. In that report [1], they have published an extensive theoretical treatment corresponding to substrate and product distribution in membranes containing enzymes. Later, Sundaram and Laidler [2] reported equations that describe the kinetics of reaction in an enzyme membrane immersed in a substrate solution. Kasche and coworkers [3] presented a model and equations that describe steady-state catalysis by an enzyme immobilized in spherical gel particles. Furthermore, they have demonstrated that the catalysis by a bounded enzyme at low substrate concentrations differs from the catalysis brought about by an unbound enzyme.
Blaedel et al. [4] derived equations for steady-state fluxes of substrates and product through a membrane in simple systems.

Catalytic biosensors are sensors that use enzymes which catalyse a specific conversion of analyte [5]. The analysis of the action of the biosensors containing one and two enzymes was performed under internal diffusion limitation in [6]. Gough et al. [7] have simulated the performance of a cylindrical biosensor employed for glucose monitoring at steady state. Jobst et al. [8] reported a finite difference scheme for the discretization of the model equation. Bacha et al. [9, 10] have developed a model that takes into account a variety of configuration designs to describe the behaviour of an amperometric biosensor for glucose monitoring. Recently, Baronas et al. [11-14] have developed a theoretical model to examine the dynamic response of amperometric biosensors under stirred and nonstirred solutions. Coche-Guerente et al. [15] analyzed the amperometric response of PPO-based rotating disk bioelectrodes based on the kinetic model by considering the internal and external mass transport effects and a CEC' electroenzymatic mechanism. 
Amperometric biosensors are rapid, sensitive, and highly stable candidates for environmental, clinical, and industrial applications. The general features of amperometric biosensors have been studied and analyzed extensively in the literature [16, 17]. However, due to the limited calculation possibilities and lack of model, the calculations were restricted by two critical concentrations of substrate (when enzyme acted at the first- and zero-order reaction conditions). Later, there are few reports that reported steadystate and nonstationary kinetics of amperometric biosensor response [17-21]. Baronas et al. [22] developed the model based on nonstationary diffusion equations containing a nonlinear term related to the enzymatic reaction. Ames [23] performed the digital simulation of the biosensor response with the implicit difference scheme.

Recently, Coche-Guerente et al. [24, 25] presented a theoretical analysis of the transport and kinetics of substrate and product in an immobilized enzyme layer involving an electrochemical substrate-recycling scheme. Baronas et al. [26] developed the mathematical model of the biosensor action to investigate the dynamics of the response of biosensors utilizing a triggered enzymatic reaction followed by the electrochemical and enzymatic product cyclic conversion scheme (CEC scheme). To the best of our knowledge, there are no analytical expressions corresponding to the steadystate substrate, product concentrations, and current for all values of parameters $\mu_{1}, \mu_{2}, \alpha_{1}$, and $\alpha_{2}$ at the rotating disk electrode for reciprocal competitive inhibition process [15]. These parameters are explained below (8). The purpose of this communication is to derive an analytical expression of steady-state concentration and current at electrodes for all values of parameters $\mu_{1}, \mu_{2}, \alpha_{1}$, and $\alpha_{2}$.

\section{Mathematical Formulation of the Problem and Analysis}

The complete mathematical formulation of this problem is described in Coche-Guerente et al. [15]. Figure 1 shows the schematic representation of a rotating disk electrode modified by a PPO enzymatic layer of thickness $L$ [15]. The enzymatic reaction of substrates $S_{1}, S_{2}$ and the product $P_{2}$ follows reciprocal competitive inhibition process. Therefore, enzymatic rate of formation of $o$-quinone from phenol and catechol substrates, $V_{1}$ and $V_{2}$ can be expressed as follows:

$$
\begin{aligned}
& V_{1}=\frac{k_{1}\left[E_{T}\right]\left[S_{1}\right]}{\left[S_{1}\right]+K_{1}\left(1+\left[S_{2}\right] / K_{2}\right)}, \\
& V_{2}=\frac{k_{2}\left[E_{T}\right]\left[S_{2}\right]}{\left[S_{2}\right]+K_{2}\left(1+\left[S_{1}\right] / K_{1}\right)},
\end{aligned}
$$

where $\left[E_{T}\right]$ represent the total concentration of active enzyme. $K_{1}, K_{2}, k_{1}$, and $k_{2}$ are the kinetic parameters. The nonlinear differential equations corresponding to the reciprocal competitive inhibition process with concentrations
$S_{1}, S_{2}$ and $P_{2}$ within the enzymatic layer $[15,26]$ at steady state condition can be written as follows:

$$
\begin{gathered}
\frac{\partial^{2}\left[S_{1}\right]}{\partial X^{2}}-\frac{\left[S_{1}\right]}{\Lambda_{1}^{2}\left(1+\left[S_{1}\right] / K_{1}+\left[S_{2}\right] / K_{2}\right)}=0, \\
\frac{\partial^{2}\left[S_{2}\right]}{\partial X^{2}}-\frac{\left[S_{2}\right]}{\Lambda_{2}^{2}\left(1+\left[S_{1}\right] / K_{1}+\left[S_{2}\right] / K_{2}\right)}=0, \\
\frac{\partial^{2}\left[P_{2}\right]}{\partial X^{2}}+\frac{\left[S_{1}\right]}{\Lambda_{1}^{2}\left(1+\left[S_{1}\right] / K_{1}+\left[S_{2}\right] / K_{2}\right)} \\
+\frac{\left[S_{2}\right]}{\Lambda_{2}^{2}\left(1+\left[S_{1}\right] / K_{1}+\left[S_{2}\right] / K_{2}\right)}=0,
\end{gathered}
$$

where $X$ represents the distance from the electrode surface, $\Lambda_{1}$ and $\Lambda_{2}$ are the reaction lengths related to phenol substrate $S_{1}$, and catechol substrate $S_{2}$. Further, $\Lambda_{1}=$ $\left(D_{f} K_{1} / k_{1}\left[E_{T}\right]\right)^{1 / 2}, \Lambda_{2}=\left(D_{f} K_{2} / k_{2}\left[E_{T}\right]\right)^{1 / 2}$, where $D_{f}$ is the diffusion coefficient in the enzymatic layer. These equations are solved for the following initial and boundary conditions as described in the literature [15]:

$$
\begin{gathered}
\frac{\partial\left[S_{1}\right]}{\partial X}=0, \quad\left[S_{1}\right]+\left[S_{2}\right]=\left[S_{1}\right]_{\infty}, \quad\left[P_{2}\right]=0 \quad \text { when } X=0, \\
{\left[S_{1}\right]=\left[S_{1}\right]_{\infty}, \quad\left[S_{2}\right]=0, \quad\left[P_{2}\right]=0 \quad \text { when } X=L+\delta .}
\end{gathered}
$$

In addition, the mass conservation implies that $\left[S_{1}\right]+\left[S_{2}\right]+$ $\left[P_{2}\right]=\left[S_{1}\right]_{\infty}$ when $X \geq L^{+}$, where $L$ is the thickness of the enzymatic layer and $\delta$ is the thickness of the diffusion convection. At $X=L$, the fluxes $J_{S_{1}}, J_{S_{2}}$, and $J_{P_{1}}$ of $S_{1}, S_{2}$, and $P_{2}$ on each side of the interface are equal [15]. Next, we introduce the following set of dimensionless variables:

$$
u=\frac{\left[S_{1}\right]}{\left[S_{1}\right]_{\infty}}, \quad v=\frac{\left[S_{2}\right]}{\left[S_{1}\right]_{\infty}}, \quad w=\frac{\left[P_{2}\right]}{\left[S_{1}\right]_{\infty}}, \quad x=\frac{X}{L},
$$

where $u, v$, and $w$ represent dimensionless concentration and $x$ is the distance parameter. The dimensionless nonlinear equations for rotating disk electrode are as follows:

$$
\begin{gathered}
\frac{\partial^{2} u}{\partial x^{2}}-\frac{\mu_{1} u}{1+\alpha_{1} u+\alpha_{2} v}=0, \\
\frac{\partial^{2} v}{\partial x^{2}}-\frac{\mu_{2} v}{1+\alpha_{1} u+\alpha_{2} v}=0, \\
\frac{\partial^{2} w}{\partial x^{2}}+\frac{\mu_{1} u}{1+\alpha_{1} u+\alpha_{2} v}+\frac{\mu_{2} v}{1+\alpha_{1} u+\alpha_{2} v}=0,
\end{gathered}
$$

where

$$
\mu_{1}=\frac{L^{2}}{\Lambda_{1}^{2}}, \quad \mu_{2}=\frac{L^{2}}{\Lambda_{2}^{2}}, \quad \alpha_{1}=\frac{\left[S_{1}\right]_{\infty}}{K_{1}}, \quad \alpha_{2}=\frac{\left[S_{1}\right]_{\infty}}{K_{2}},
$$

where $\mu_{1}$ is the ratio of the square of the thickness $L$ and the reaction length $\Lambda_{1} ; \mu_{2}$ is the ratio of the square of the thickness $L$ and the reaction length $\Lambda_{2} ; \alpha_{1}$ is the ratio of $\left[S_{1}\right]_{\infty}$ and the kinetic parameter $K_{1} ; \alpha_{2}$ is the ratio of $\left[S_{1}\right]_{\infty}$ and the kinetic parameter $K_{2}$. Now the initial and boundary conditions are given by the following equation:

$$
\begin{gathered}
\frac{\partial u}{\partial x}=0, \quad u+v=1, \quad w=0 \quad \text { when } x=0, \\
u=1, \quad v=0, \quad w=0 \quad \text { when } x=1+\frac{\delta}{L}=m .
\end{gathered}
$$


The dimensionless current is given by [15]

$$
I=\frac{j_{f}}{2 F}=-\left(\frac{\partial v}{\partial x}\right)_{x=0},
$$

where $F$ is the Faraday constant.

\section{Solution of Boundary Value Problem Using the Homotopy Perturbation Method}

The HPM [27] uses the embedded parameter $p$ as small, and only a few iterations are essential for an asymptotic solution. Using this method (see Appendix A), the solutions to (5)-(7) can be deduced as follows:

$$
\begin{aligned}
u(x)=a \cosh ( & \left.\sqrt{\mu_{1}} x\right) \\
+\alpha_{2} A_{0} & {\left[2 a \cosh \left(\sqrt{\mu_{2}} m\right)\left(\mu_{2}-2 \mu_{1}\right) \sqrt{\mu_{2}}\right.} \\
& \times \sinh \left(\sqrt{\mu_{1}}(m-x)\right) \\
+ & 4 a \mu_{1} \sqrt{\mu_{2}} \sinh \left(\sqrt{\mu_{1}} m\right) \cosh \left(\sqrt{\mu_{1}} x\right) \\
& -\left(\mu_{2}+2 \sqrt{\mu_{1} \mu_{2}}\right) \sqrt{\mu_{1}} \sinh \left(\sqrt{\mu_{1}} x+\sqrt{\mu_{2}}(m-x)\right) \\
& -\left(\mu_{2}-2 \sqrt{\mu_{1} \mu_{2}}\right) \sqrt{\mu_{1}} \\
& \left.\times \sinh \left(-\sqrt{\mu_{1}} x+\sqrt{\mu_{2}}(m-x)\right)\right] \\
+\frac{\alpha_{1} a^{2}}{6} & {\left[a \cosh \left(\sqrt{\mu_{1}} x\right) \cosh \left(2 \sqrt{\mu_{1}} m-3\right)\right.} \\
& \left.-\cosh \left(2 \sqrt{\mu_{1}} x\right)+3\right]
\end{aligned}
$$

$$
\begin{aligned}
& v(x)=(1-a) b \sinh \left(\sqrt{\mu_{2}}(m-x)\right)-\alpha_{2} A_{0} \sinh \left(\sqrt{\mu_{2}}(m-x)\right) \\
& \times\left(2 a b \sqrt{\mu_{2}} \sinh \left(\sqrt{\mu_{1}} m\right)\right. \\
&\left.\quad \times\left(\cosh \left(\sqrt{\mu_{2}} m\right)\left(\mu_{2}-2 \mu_{1}\right)+2 \mu_{1}\right)-2 \sqrt{\mu_{1}} \mu_{2}\right) \\
&+A_{1}\left[2 \mu_{1} \sinh \left(\sqrt{\mu_{2}}(m-x)\right)+4 b \sqrt{\mu_{1}} \sqrt{\mu_{2}} \sinh \left(\sqrt{\mu_{1}} m\right)\right. \\
& \quad \times \sinh \left(\sqrt{\mu_{2}} x\right)-\left(\mu_{1}+2 \sqrt{\mu_{1}} \sqrt{\mu_{2}}\right) \\
& \quad \times \sinh \left(\sqrt{\mu_{1}} x+\sqrt{\mu_{2}}(m-x)\right) \\
&\left.\quad-\left(\mu_{1}-2 \sqrt{\mu_{1}} \sqrt{\mu_{2}}\right) \sinh \left(-\sqrt{\mu_{1}} x+\sqrt{\mu_{2}}(m-x)\right)\right] \\
&-\alpha_{1} a^{2} b \sinh \left(\sqrt{\mu_{2}}(m-x)\right) \\
& \times\left(\frac{a\left(\cosh \left(2 \sqrt{\mu_{1}} m\right)-3\right)}{6}+\frac{1}{3}\right) \\
&+A_{2}\left[\left(\cosh \left(2 \sqrt{\mu_{2}} m\right)+3\right) \sinh \left(\sqrt{\mu_{2}}(m-x)\right)\right.
\end{aligned}
$$

$$
\begin{aligned}
& +4 \sinh \left(\sqrt{\mu_{2}} x\right)-\sinh \left(\sqrt{\mu_{2}} m\right) \\
& \left.\times\left(\cosh \left(2 \sqrt{\mu_{2}}(m-x)\right)+3\right)\right],
\end{aligned}
$$

where $a=1 /\left(\cosh \left(\sqrt{\mu_{1}} m\right)\right) ; b=1 /\left(\sinh \left(\sqrt{\mu_{2}} m\right)\right) ; A_{0}=$ $\left(a(1-a) b \sqrt{\mu_{1}}\right) /\left(2\left(\mu_{2}^{2}-4 \mu_{1} \mu_{2}\right)\right) ; A_{1}=\left(\alpha_{1} \mu_{2} a b(1-a)\right) /\left(2\left(\mu_{1}^{2}-\right.\right.$ $\left.\left.4 \mu_{1} \mu_{2}\right)\right) ; A_{2}=\left(\alpha_{2}(1-a)^{2} b^{3}\right) / 6$. Adding (5) and (6) using the boundary conditions $(9)$, we can obtain

$$
w(x)=1-u(x)-v(x) .
$$

Equations (11)-(13) are the analytical expressions corresponding to the dimensionless concentrations as a function of dimensionless distance $x$. These equations satisfy the boundary conditions (9). When $\alpha_{1}$ and $\alpha_{2} \rightarrow 0$ ( $K_{1}$ and $\left.K_{2} \rightarrow \infty\right)$, the concentrations $u, v$, and $w$ become

$$
\begin{gathered}
u(x)=a \cosh \left(\sqrt{\mu_{1}} x\right), \\
v(x)=(1-a) b \sinh \left(\sqrt{\mu_{2}}(m-x)\right), \\
w(x)=1-u(x)-v(x) .
\end{gathered}
$$

Using (10) the current density is

$$
\begin{aligned}
& I=(1-a) b \sqrt{\mu_{2}} \cosh \left(\sqrt{\mu_{2}} m\right)-\alpha_{2} A_{0} \sqrt{\mu_{2}} \cosh \left(\sqrt{\mu_{2}} m\right) \\
& \times\left(2 a b \sqrt{\mu_{2}} \sinh \left(\sqrt{\mu_{1}} m\right)\right. \\
&\left.\times\left(\cosh \left(\sqrt{\mu_{2}} m\right)\left(\mu_{2}-2 \mu_{1}\right)+2 \mu_{1}\right)-2 \sqrt{\mu_{1}} \mu_{2}\right) \\
&+ A_{1}\left[2 \mu_{1} \sqrt{\mu_{2}} \cosh \left(\sqrt{\mu_{2}} m\right)-4 b \sqrt{\mu_{1}} \mu_{2} \sinh \left(\sqrt{\mu_{1}} m\right)\right. \\
&+\left(\mu_{1}+2 \sqrt{\mu_{1}} \sqrt{\mu_{2}}\right) \cosh \left(\sqrt{\mu_{2}} m\right)\left(\sqrt{\mu_{1}}-\sqrt{\mu_{2}}\right) \\
&-\left.-\left(\mu_{1}-2 \sqrt{\mu_{1}} \sqrt{\mu_{2}}\right) \cosh \left(\sqrt{\mu_{2}} m\right)\left(\sqrt{\mu_{1}}+\sqrt{\mu_{2}}\right)\right] \\
& \times\left(\frac{a\left(\cosh \left(2 \sqrt{\mu_{1}} m\right)-3\right)}{6} \cosh \left(\sqrt{\mu_{2}} m\right)\right. \\
&+ A_{2}\left[\left(\cosh \left(2 \sqrt{\mu_{2}} m\right)+3\right) \sqrt{\mu_{2}} \cosh \left(\sqrt{\mu_{2}} m\right)-4 \sqrt{\mu_{2}}\right. \\
&\left.-2 \sqrt{\mu_{2}} \sinh \left(\sqrt{\mu_{2}} m\right) \sinh \left(2 \sqrt{\mu_{2}} m\right)\right] .
\end{aligned}
$$

Equation (15) represents the dimensionless current as a function of dimensionless parameters $\mu_{1}, \mu_{2}, \alpha_{1}, \alpha_{2}$, and $m$.

\section{Numerical Simulation}

The system of steady-state nonlinear differential equations (5)-(7) are also solved in numerical methods. The function pdex4 in Scilab/Matlab software which is a function of solving partial differential equations is used to solve these equations. Its numerical solution is compared with the analytical solution obtained by HPM. Satisfactory agreement is noted. The Scilab/Matlab program is also given in Appendix B. 


\section{Results and Discussion}

5.1. Concentration Profiles. Equations (11)-(13) are the new and simple analytical expressions of concentrations of phenol (substrate $u\left(\mu_{1}, \mu_{2}, \alpha_{1}, \alpha_{2}, \delta / L\right)$ ), catechol (substrate $v\left(\mu_{1}, \mu_{2}, \alpha_{1}, \alpha_{2}, \delta / L\right)$ ), and $o$-quinone (product $\left.w\left(\mu_{1}, \mu_{2}, \alpha_{1}, \alpha_{2}, \delta / L\right)\right)$, respectively. All substrate molecules are enzymatically oxidized within the enzymatic layer before reaching the electrode surface. Thus, the high sensitivity observed with a PPO bioelectrode working at a cathodic potential can be explained by an efficient electrochemical recycling of substrate which can enter a new enzymatic step in the proximity of the enzymatic layer interface. This interpretation agrees well with the substrates and product concentration profiles in the enzymatic layer calculated on the basis of (11)-(13) and reproduced in Figures 24. In these figures, the profiles of substrates (phenol and catechol) as well as product (o-quinone) concentration in the enzyme layer are presented for biosensor acting in CEC mechanism. The thickness of the enzymatic layer constitutes an important parameter that governs the biosensor sensitivity. The normalized concentration of phenol substrate $u$ is represented in Figures 2(a)-2(c). From this figure, it is evident that the value of phenol substrate concentration $u$ decreases when the thickness of the enzymatic layer increases and enzyme activity increases $\left(\mu_{1}, \mu_{2}\right.$ increase) for all values of $\alpha_{1}$ and $\delta / L$. The concentration of phenol substrate $u$ is equal to 1 when $\mu_{1} \leq 0.1$ and $u$ becomes zero when $\mu_{1} \geq$ 30 for all values $\alpha_{1}$ and $\mu_{2}$. Figures 3(a)-3(c) stand for the normalized concentration profile of catechol $v$. It is clear that the catechol concentration $v$ increases when the thickness of the enzymatic layer increases. The concentration of catechol substrate $v$ becomes zero when $\mu_{1} \leq 0.1$ for all values of parameters. Figures 4(a)-4(c) represent the normalized $o$ quinone concentration $w$. It is clear that the concentration of $o$-quinone $w$ increases when the thickness of the enzymatic layer increases. The concentration of $o$-quinone product $w$ reaches the maximum value when $x=0.3$ and then decreases to the minimum value zero when the diffusion-convection layer is equal to zero.

5.2. Current Response. The analytical expression of steadystate current $I\left(\mu_{1}, \mu_{2}, \alpha_{1}, \alpha_{2}, \delta / L\right)$ is given in (15). The steady-state current of membrane biosensors significantly depends on the thickness of the enzymatic layer. Figures 5(a) and 5(b) show the dimensionless current $I$ for all values of parameters $\mu_{1}, \mu_{2}, \alpha_{1}$ and $\alpha_{2}$. From these figures it is inferred that the current increases gradually when $\mu_{1}$ and $\mu_{2}$ increase. When $\mu_{2} \rightarrow 0$ at any $\mu_{1}>0$ current $I \rightarrow 0$ (refer to Figure 5(b)). Figures 5(c) and 5(d) represent the dimensionless current I for all values of kinetic parameters. From these figures it is evident that the current decreases when $\alpha_{1}$ and $\alpha_{2}$ increase. The current $I$ is monotonously increasing function of both arguments $\mu_{1}$ and $\mu_{2}$. In the case of CEC mode an application of an active enzyme $\left[E_{T}\right]$ $\left(\mu_{2}>0\right)$ stimulates an increase of the biosensor current. The steady-state current of membrane biosensor significantly depends on the thickness of the enzyme layer $(L)$. In view

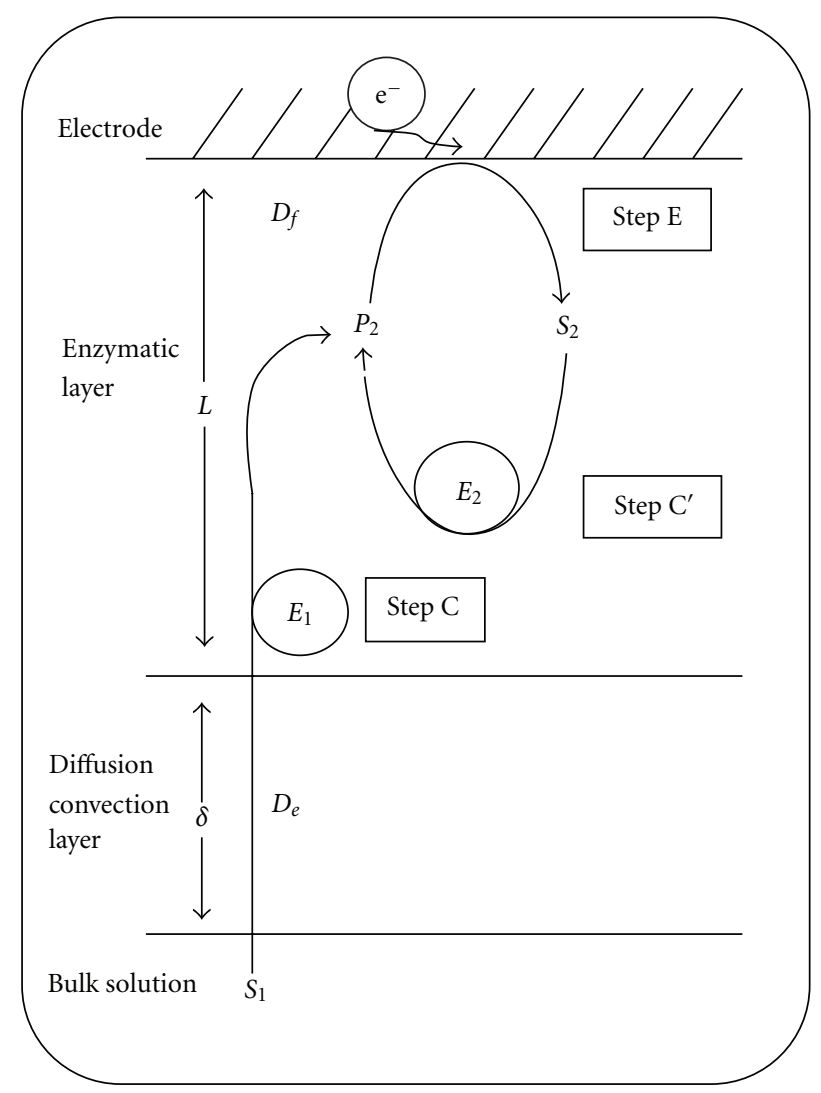

FIGURE 1: Schematic representation of rotating disk electrode modified by a PPO enzymatic layer and principle of the bioelectrode functioning in the presence of phenol substrates $S_{1}, S_{2}$ and product $P_{2}$ [15].

of biosensor optimizations, it can be seen that the current $I$ (refer to Figure 5(e)) is higher for low electrode rotation rate and small thickness of enzymatic layer.

\section{Conclusions}

This paper reports a mathematical treatment for analyzing amperometric enzymatic reactions. In this paper, we have evaluated a theoretical model for a rotating disk electrode based on an immobilized enzyme layer. The novelty of this paper is an application of approximate method to the second-order nonlinear partial differential equations. The approximate analytical expressions for the steady state substrate concentrations and product concentration profiles for all values of $\mu_{1}, \mu_{2}, \alpha_{1}$ and $\alpha_{2}$ at the rotating disk electrode were obtained using Homotopy perturbation method. Furthermore, an analytical expression corresponding to the steady state current response is also presented. A satisfactory agreement with the existing limiting cases results is noted. The results presented in the paper extend to many applications related to biosensors modeling. 


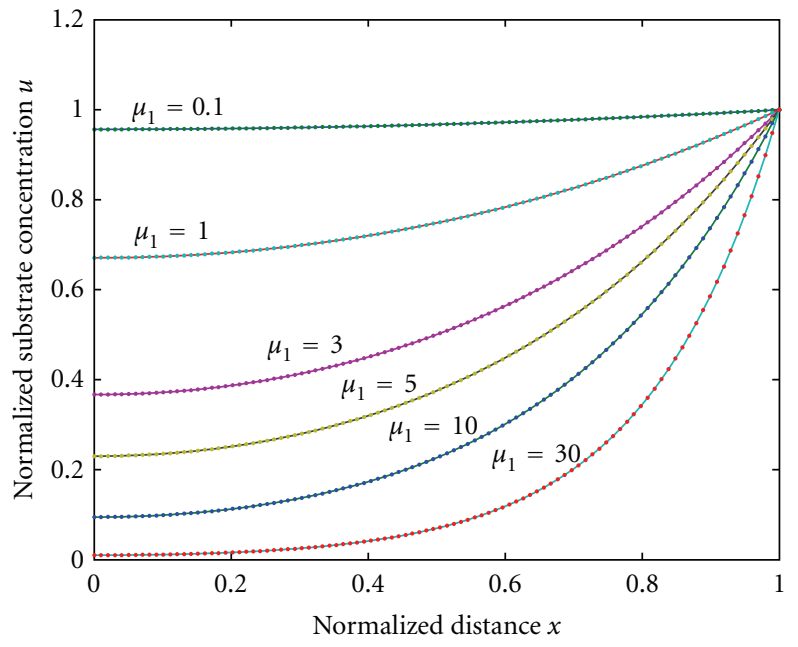

(a)

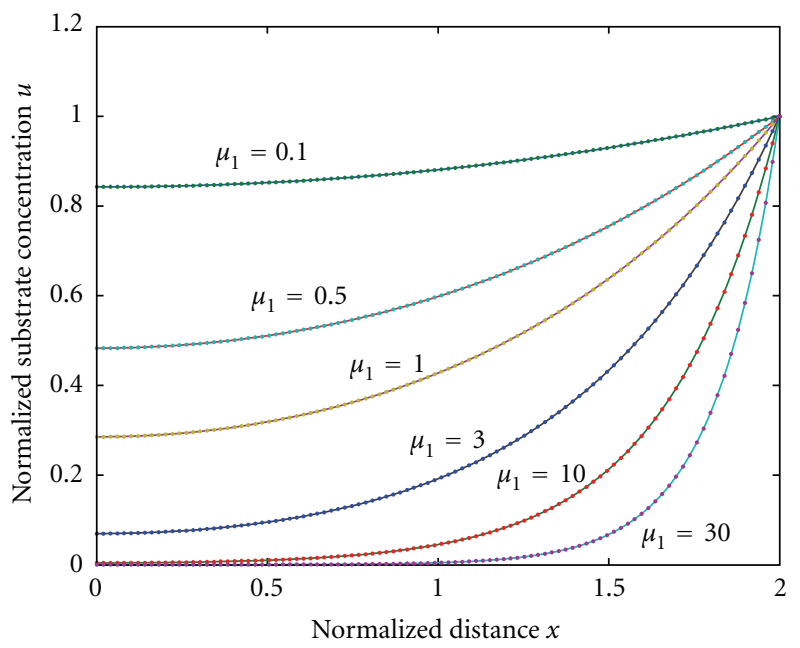

(c)

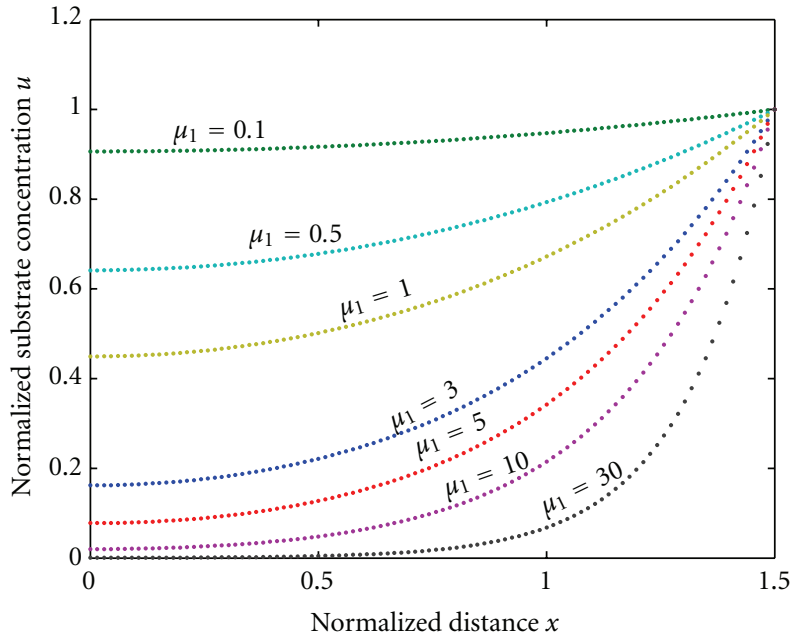

(b)

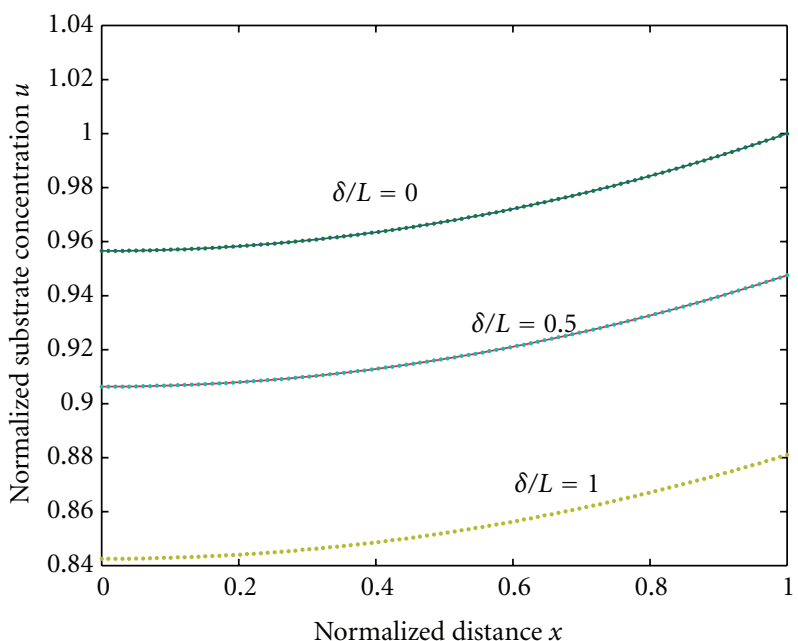

(d)

FIGURE 2: The profile of the normalized concentration of phenol substrate $u$ versus the normalized distance $x$. The concentrations were computed using (11) when the parameters $\mu_{2}=1, \alpha_{1}=0.1, \alpha_{2}=0.1$ and for various values of $\mu_{1}$ and $\delta / L$. The key to the graph (stacked line) represents (11) and (dotted line) represents the numerical solution. (a) $\delta / L=0$, (b) $\delta / L=0.5$, (c) $\delta / L=1$, (d) $\mu_{1}=0.1$.

\section{Appendices}

\section{A. Solution of (5)-(7) Using Homotopy Perturbation Method}

In this appendix, we indicate how (11)-(13) in this paper are deduced. In order to obtain the solution of (5)-(7), we first construct a Homotopy as follows:

$$
\begin{aligned}
& (1-p)\left[\frac{\partial^{2} u}{\partial x^{2}}-\mu_{1} u\right] \\
& \quad+p\left[\frac{\partial^{2} u}{\partial x^{2}}-\mu_{1} u+\alpha_{1} u \frac{\partial^{2} u}{\partial x^{2}}+\alpha_{2} v \frac{\partial^{2} u}{\partial x^{2}}\right]=0
\end{aligned}
$$

$$
\begin{aligned}
& (1-p)\left[\frac{\partial^{2} v}{\partial x^{2}}-\mu_{2} v\right] \\
& +p\left[\frac{\partial^{2} v}{\partial x^{2}}-\mu_{2} v+\alpha_{1} u \frac{\partial^{2} v}{\partial x^{2}}+\alpha_{2} v \frac{\partial^{2} v}{\partial x^{2}}\right]=0
\end{aligned}
$$

The approximate solutions of (A.1) are

$$
\begin{gathered}
u=u_{0}+p u_{1}+p^{2} u_{2}+p^{3} u_{3}+\cdots \\
v=v_{0}+p v_{1}+p^{2} v_{2}+p^{3} v_{3}+\cdots
\end{gathered}
$$




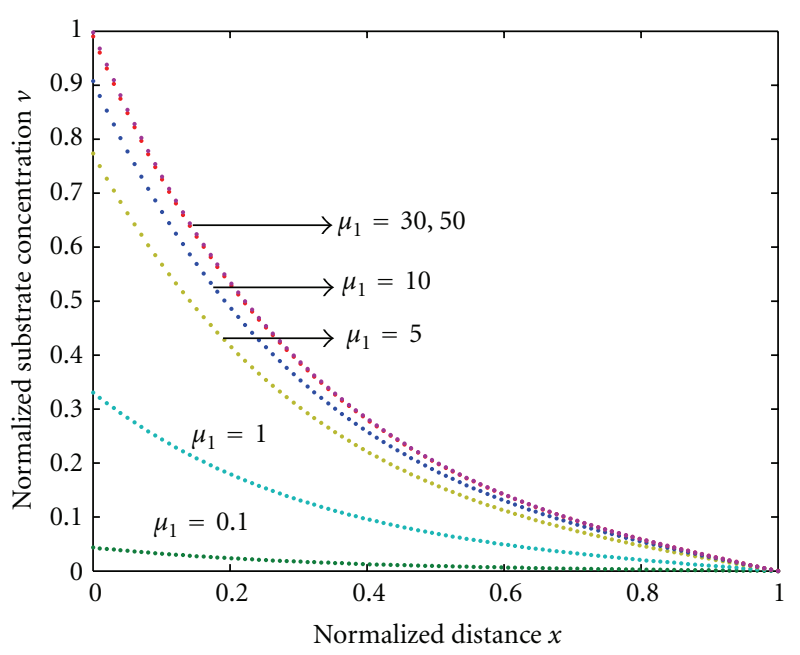

(a)

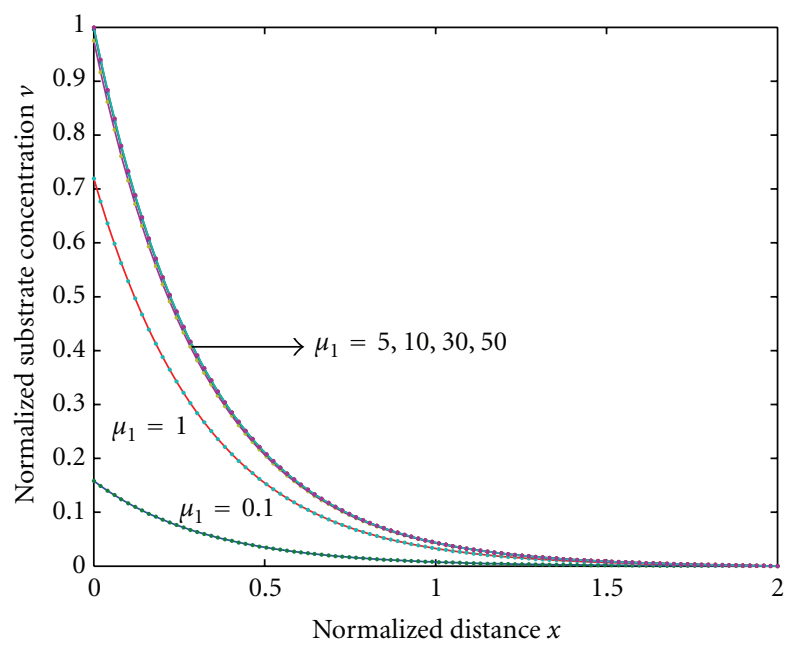

(c)

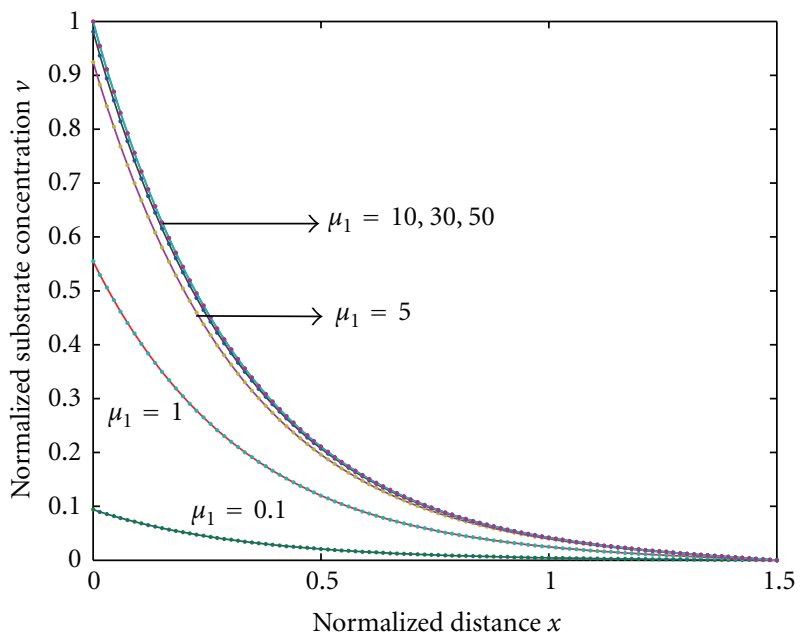

(b)

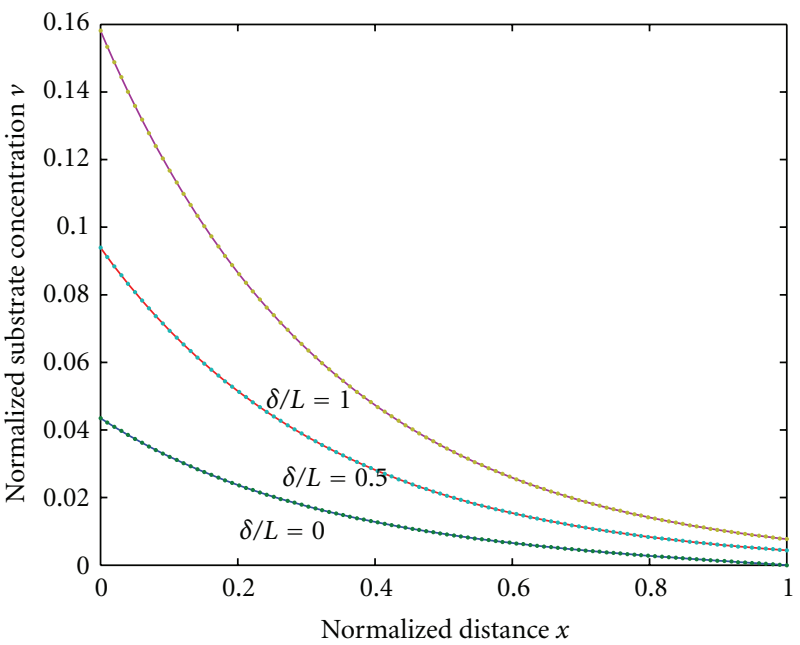

(d)

FIgURE 3: The profile of the normalized concentration of catechol substrate $v$ versus the normalized distance $x$. The concentrations were computed using (12) when the parameters $\mu_{2}=10, \alpha_{1}=0.1, \alpha_{2}=0.1$ and for various values of $\mu_{1}$ and $\delta / L$. The key to the graph (stacked line) represents (12) and (dotted line) represents the numerical solution. (a) $\delta / L=0,(\mathrm{~b}) \delta / L=0.5,(\mathrm{c}) \delta / L=1$, (d) $\mu_{1}=0.1$.

Substituting (A.2) into (A.1) and comparing the coefficients of like powers of $p$

$$
\begin{aligned}
& p^{0}: \frac{\partial^{2} u_{0}}{\partial x^{2}}-\mu_{1} u_{0}=0, \\
& p^{1}: \frac{\partial^{2} u_{1}}{\partial x^{2}}-\mu_{1} u_{1}+\alpha_{1} u_{0} \frac{\partial^{2} u_{0}}{\partial x^{2}}+\alpha_{2} v_{0} \frac{\partial^{2} u_{0}}{\partial x^{2}}=0 \\
& p^{0}: \frac{\partial^{2} v_{0}}{\partial x^{2}}-\mu_{2} v_{0}=0, \\
& p^{1}: \frac{\partial^{2} v_{1}}{\partial x^{2}}-\mu_{2} v_{1}+\alpha_{1} u_{0} \frac{\partial^{2} v_{0}}{\partial x^{2}}+\alpha_{2} v_{0} \frac{\partial^{2} v_{0}}{\partial x^{2}}=0
\end{aligned}
$$

The boundary conditions are

$$
\begin{gathered}
\frac{\partial u_{0}}{\partial x}=0, \quad u_{0}+v_{0}=1 \quad \text { when } x=0, \\
u_{0}=1, \quad v_{0}=0 \quad \text { when } x=1+\frac{\delta}{L}=m, \\
\frac{\partial u_{1}}{\partial x}=0, \quad u_{1}+v_{1}=0 \quad \text { when } x=0, \\
u_{1}=0, \quad v_{1}=0 \quad \text { when } x=1+\frac{\delta}{L}=m
\end{gathered}
$$




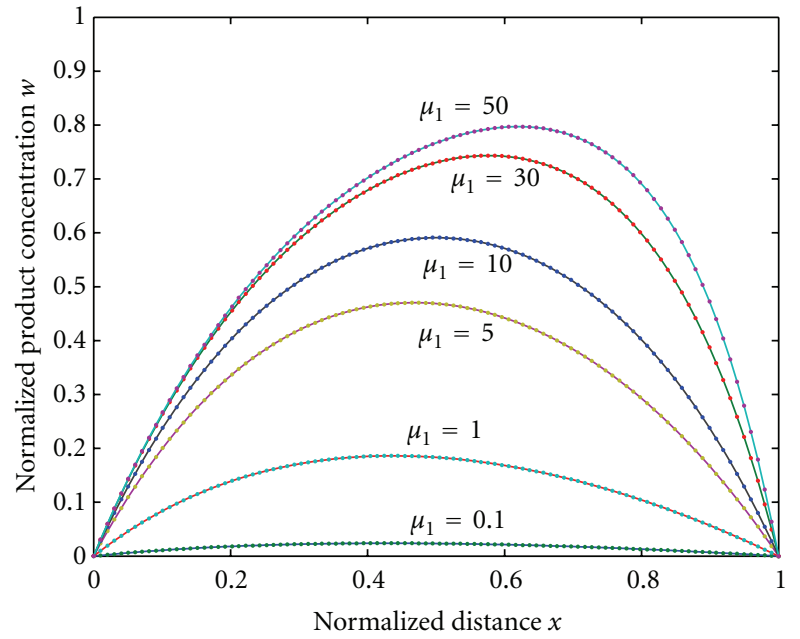

(a)

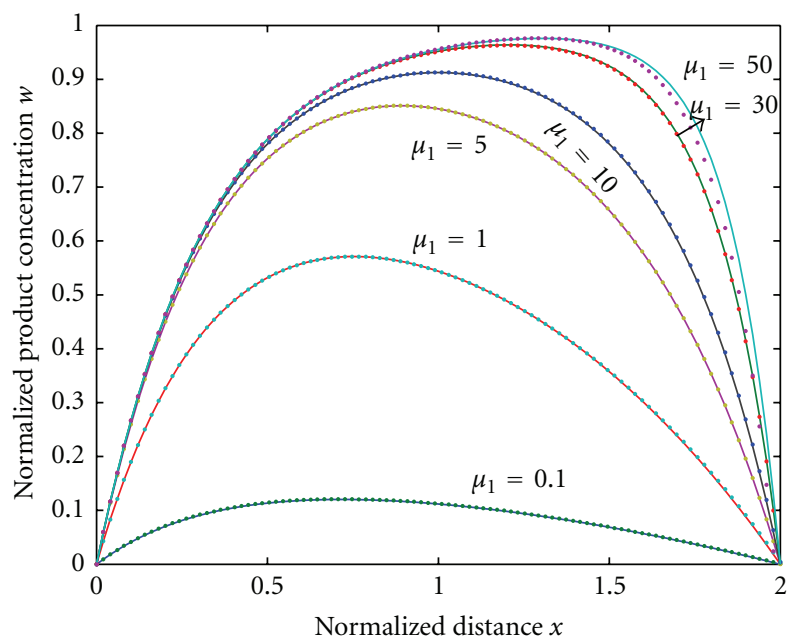

(c)

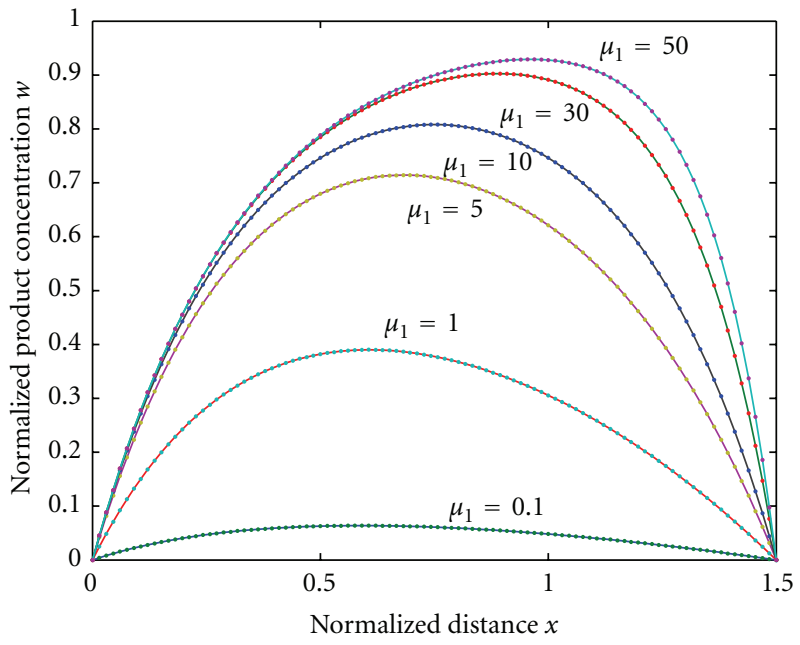

(b)

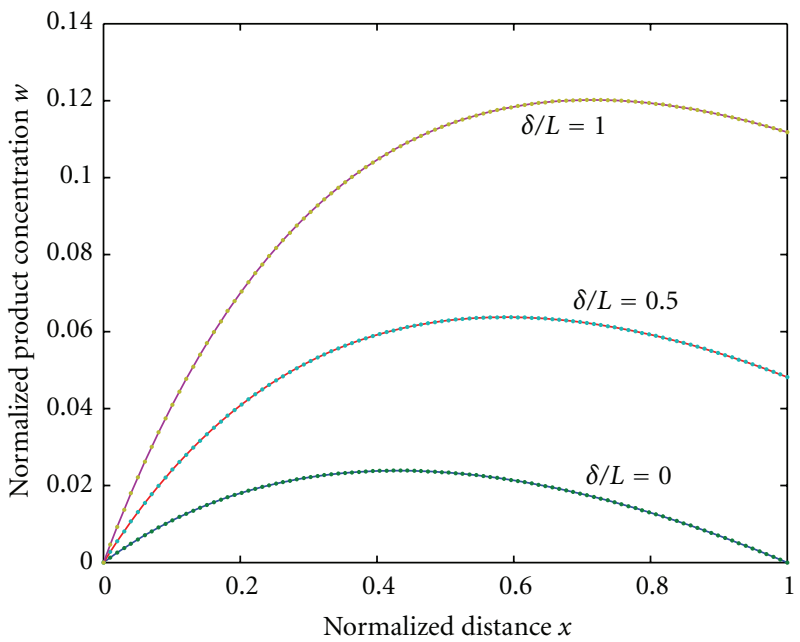

(d)

FIGURE 4: The profile of the normalized concentration of $o$-quinone product $w$ versus the normalized distance $x$. The concentrations were computed using (13) when the parameters $\mu_{2}=10, \alpha_{1}=0.1, \alpha_{2}=0.1$ and for various values of $\mu_{1}$ and $\delta / L$. The key to the graph (stacked line) represents (13) and (dotted line) represents the numerical solution. (a) $\delta / L=0$, (b) $\delta / L=0.5$, (c) $\delta / L=1$, (d) $\mu_{1}=0.1$.

Solving (A.3) using the boundary conditions (A.4), we can obtain

$$
\begin{aligned}
& u_{0}=a \cosh \left(\sqrt{\mu_{1}} x\right) \\
& \begin{aligned}
u_{1}=\alpha_{2} A_{0}[2 & a \cosh \left(\sqrt{\mu_{2}} m\right)\left(\mu_{2}-2 \mu_{1}\right) \\
& \times \sqrt{\mu_{2}} \sinh \left(\sqrt{\mu_{1}}(m-x)\right) \\
& +4 a \mu_{1} \sqrt{\mu_{2}} \sinh \left(\sqrt{\mu_{1}} m\right) \cosh \left(\sqrt{\mu_{1}} x\right) \\
& -\left(\mu_{2}+2 \sqrt{\mu_{1} \mu_{2}}\right) \sqrt{\mu_{1}} \sinh \left(\sqrt{\mu_{1}} x+\sqrt{\mu_{2}}(m-x)\right) \\
& -\left(\mu_{2}-2 \sqrt{\mu_{1} \mu_{2}}\right) \sqrt{\mu_{1}} \\
& \left.\times \sinh \left(-\sqrt{\mu_{1}} x+\sqrt{\mu_{2}}(m-x)\right)\right]
\end{aligned}
\end{aligned}
$$

$$
\begin{gathered}
+\frac{\alpha_{1} a^{2}}{6}\left[a \cosh \left(\sqrt{\mu_{1}} x\right) \cosh \left(2 \sqrt{\mu_{1}} m-3\right)\right. \\
\left.-\cosh \left(2 \sqrt{\mu_{1}} x\right)+3\right]
\end{gathered}
$$$$
v_{0}=(1-a) b \sinh \left(\sqrt{\mu_{2}}(m-x)\right) \text {, }
$$$$
v_{1}=-\alpha_{2} A_{0} \sinh \left(\sqrt{\mu_{2}}(m-x)\right)
$$$$
\times\left(2 a b \sqrt{\mu_{2}} \sinh \left(\sqrt{\mu_{1}} m\right)\right.
$$$$
\times\left(\cosh \left(\sqrt{\mu_{2}} m\right)\left(\mu_{2}-2 \mu_{1}\right)+2 \mu_{1}\right)
$$$$
\left.-2 \sqrt{\mu_{1}} \mu_{2}\right)
$$ 


$$
\begin{aligned}
& +A_{1}\left[2 \mu_{1} \sinh \left(\sqrt{\mu_{2}}(m-x)\right)\right. \\
& +4 b \sqrt{\mu_{1}} \sqrt{\mu_{2}} \sinh \left(\sqrt{\mu_{1}} m\right) \sinh \left(\sqrt{\mu_{2}} x\right) \\
& -\left(\mu_{1}+2 \sqrt{\mu_{1}} \sqrt{\mu_{2}}\right) \sinh \left(\sqrt{\mu_{1}} x+\sqrt{\mu_{2}}(m-x)\right) \\
& \left.-\left(\mu_{1}-2 \sqrt{\mu_{1}} \sqrt{\mu_{2}}\right) \sinh \left(-\sqrt{\mu_{1}} x+\sqrt{\mu_{2}}(m-x)\right)\right] \\
& -\alpha_{1} a^{2} b \sinh \left(\sqrt{\mu_{2}}(m-x)\right) \\
& \times\left(\frac{a\left(\cosh \left(2 \sqrt{\mu_{1}} m\right)-3\right)}{6}+\frac{1}{3}\right) \\
& +A_{2}\left[\left(\cosh \left(2 \sqrt{\mu_{2}} m\right)+3\right) \sinh \left(\sqrt{\mu_{2}}(m-x)\right)\right. \\
& +4 \sinh \left(\sqrt{\mu_{2}} x\right)-\sinh \left(\sqrt{\mu_{2}} m\right) \\
& \left.\times\left(\cosh \left(2 \sqrt{\mu_{2}}(m-x)\right)+3\right)\right] .
\end{aligned}
$$

According to the HPM, we can conclude that

$$
\begin{aligned}
& u=\lim _{p \rightarrow 1} u(x) \approx u_{0}+u_{1}, \\
& v=\lim _{p \rightarrow 1} v(x) \approx v_{0}+v_{1} .
\end{aligned}
$$

After putting (A.5) into (A.7) and (A.6) into (A.8), the final results can be described in (11) and (12) in the text.

\section{B. Scilab/Matlab Program to Find the Numerical Solutions for (5), (6), and (7)}

function pdex 4

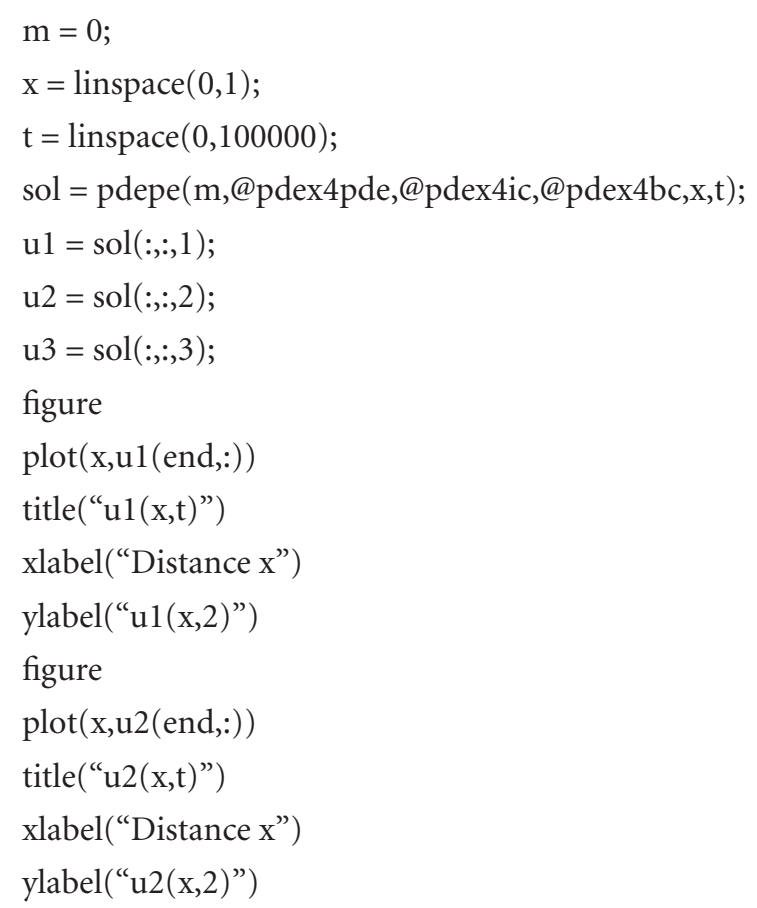

figure

$\operatorname{plot}(\mathrm{x}, \mathrm{u} 3(\mathrm{end}, \mathrm{)}))$

title(“"u3(x,t)")

xlabel(“Distance x")

ylabel(“u3(x,2)”)

function $[c, f, s]=\operatorname{pdex} 4 p d e(x, t, u, D u D x)$

$c=[1 ; 1 ; 1]$

$\mathrm{f}=[1 ; 1 ; 1] .^{*} \mathrm{DuDx}$;

$M=100$

$\mathrm{N}=0.1$;

$\mathrm{P}=1$

$\mathrm{Q}=0.1$;

$\mathrm{F}=-\mathrm{M}^{*} \mathrm{u}(1) /\left(1+\mathrm{N}^{*} \mathrm{u}(1)+\mathrm{Q}^{*} \mathrm{u}(2)\right) ;$

$\mathrm{F} 1=-\mathrm{P}^{*} \mathrm{u}(2) /\left(1+\mathrm{N}^{*} \mathrm{u}(1)+\mathrm{Q}^{*} \mathrm{u}(2)\right) ;$

$\mathrm{F} 2=-\mathrm{F}-\mathrm{F} 1$

$\mathrm{s}=[\mathrm{F} ; \mathrm{F} 1 ; \mathrm{F} 2]$

function $\mathrm{u} 0=\operatorname{pdex} 4 \mathrm{ic}(\mathrm{x})$;

$\mathrm{u} 0=[0 ; 1 ; 0]$

function $[\mathrm{pl}, \mathrm{ql}, \mathrm{pr}, \mathrm{qr}]=\operatorname{pdex} 4 \mathrm{bc}(\mathrm{xl}, \mathrm{ul}, \mathrm{xr}, \mathrm{ur}, \mathrm{t})$

$\mathrm{pl}=[0 ; \mathrm{ul}(2)-1+\mathrm{ul}(1) ; \mathrm{ul}(3)]$

$\mathrm{ql}=[1 ; 0 ; 0]$

$\operatorname{pr}=[\operatorname{ur}(1)-1 ; \operatorname{ur}(2) ; \operatorname{ur}(3)] ;$

$\mathrm{qr}=[0 ; 0 ; 0]$.

\section{Nomenclature and Units}

$\left[S_{1}\right]$ : Concentration of the phenol substrate (mole $\mathrm{cm}^{-3}$ )

$\left[S_{2}\right]$ : Concentration of the catechol substrate $\left(\right.$ mole $\mathrm{cm}^{-3}$ )

$\left[P_{2}\right]$ : Concentration of the $o$-quinone product (mole $\mathrm{cm}^{-3}$ )

$\left[S_{1}\right]_{\infty}$ : Bulk concentration of the phenol substrate $\left(\right.$ mole $\left.\mathrm{cm}^{-3}\right)$

$\left[S_{2}\right]_{\infty}$ : Bulk concentration of the catechol substrate $\left(\right.$ mole $\left.\mathrm{cm}^{-3}\right)$

$\left[P_{2}\right]_{\infty}$ : Bulk concentration of the $o$-quinone product $\left(\right.$ mole $\left.\mathrm{cm}^{-3}\right)$

$\left[E_{T}\right]$ : Enzyme concentration $\left(\right.$ mole $\left.\mathrm{cm}^{-3}\right)$

$L: \quad$ Thickness of the enzymatic layer $(\mathrm{cm})$ 


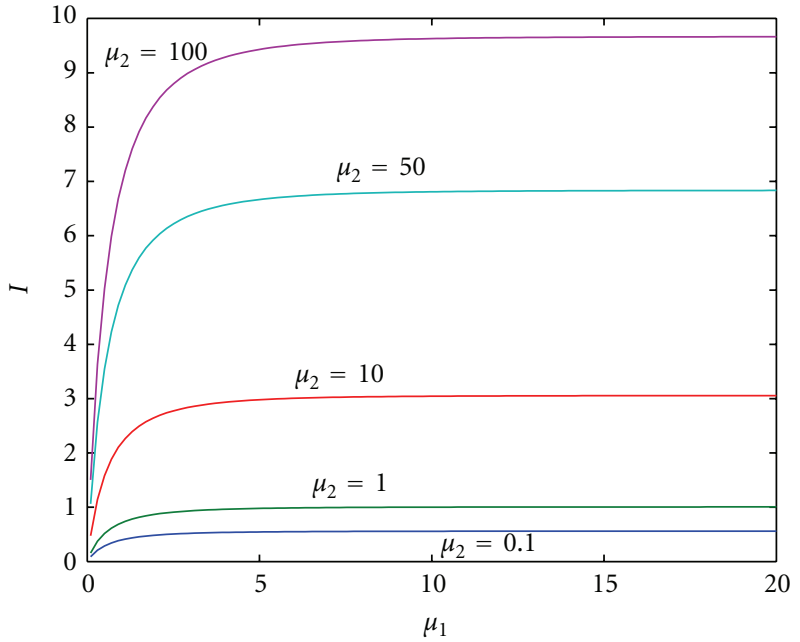

(a)

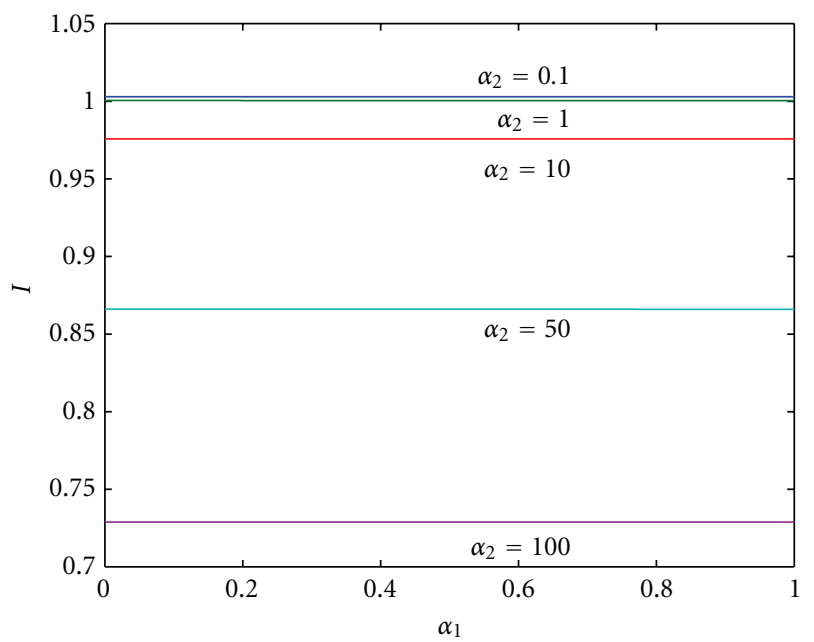

(c)

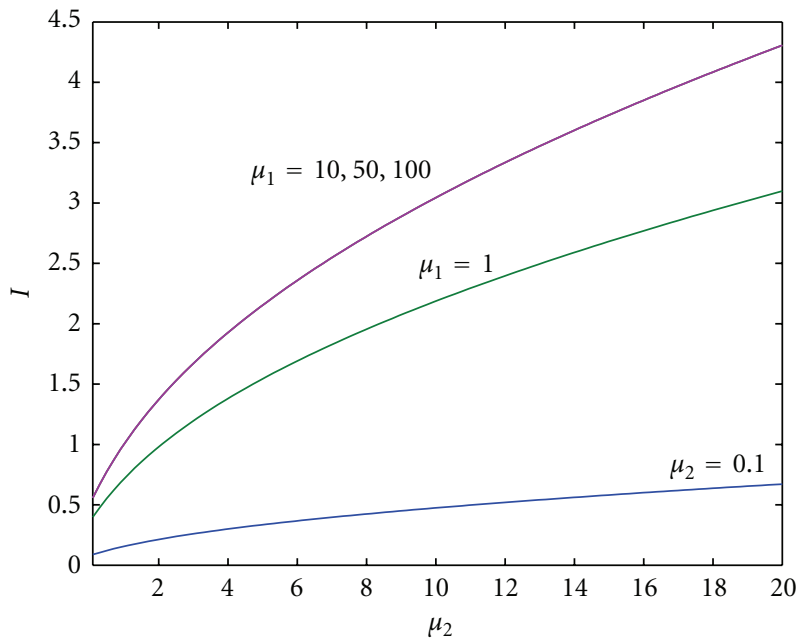

(b)

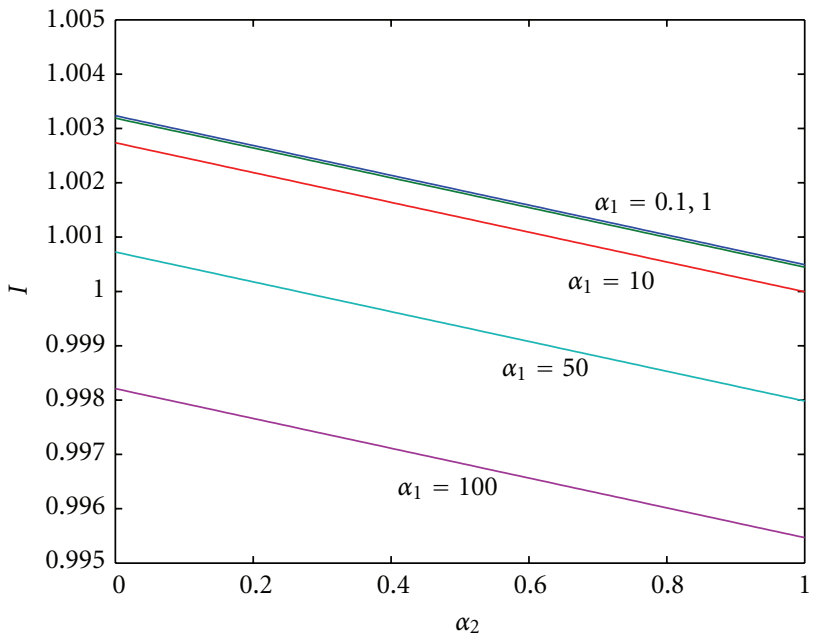

(d)

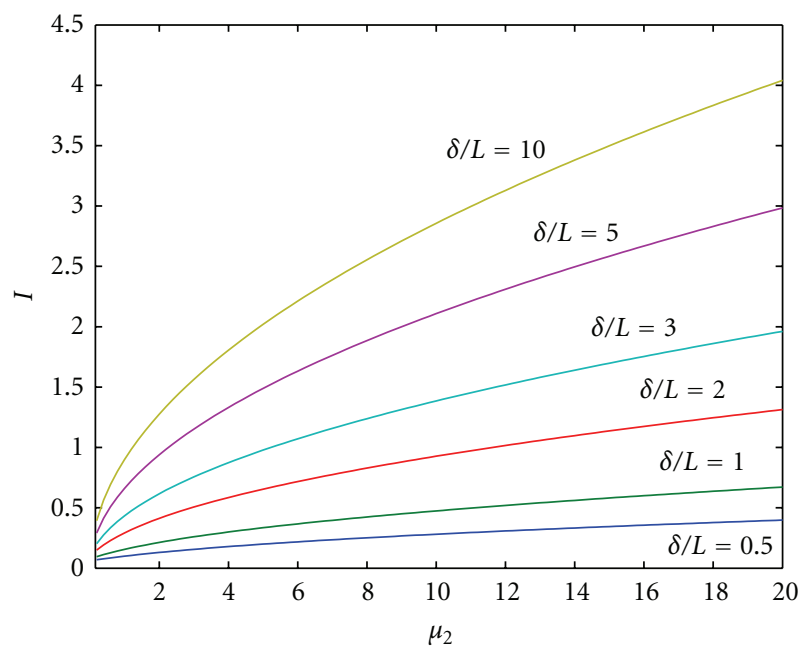

(e)

FiguRE 5: The steady state-current $I$ versus dimensionless parameters. The current is computed using (15). (a) $\alpha_{1}=0.1, \alpha_{2}=0.1, \delta / L=1$, (b) $\alpha_{1}=0.1, \alpha_{2}=0.1, \delta / L=1$, (c) $\mu_{1}=100, \mu_{2}=0.01, \delta / L=0$, (d) $\mu_{1}=100, \mu_{2}=0.01, \delta / L=0$, (e) $\mu_{1}=0.1, \alpha_{1}=0.1, \alpha_{2}=0.1$. 
$\delta: \quad$ Thickness of the diffusion-convection layer (cm)

$D_{f}$ : Diffusion coefficient in the enzymatic layer $\left(\mathrm{cm}^{2} \mathrm{~s}^{-1}\right)$

$D_{e}$ : Diffusion coefficient in the diffusion convection layer $\left(\mathrm{cm}^{2} \mathrm{~s}^{-1}\right)$

$\Lambda_{1}, \Lambda_{2}$ : Reaction lengths $(\mathrm{cm})$

$K_{1}, K_{2}$ : Kinetic parameters $\left(\right.$ mole $\mathrm{cm}^{-3}$ )

$k_{1}, k_{2}$ : Kinetic parameters $\left(\mathrm{s}^{-1}\right)$

$\mu_{1}$ : Ratio of the square of thickness of the enzymatic layer and the reaction length (None)

$\mu_{2}$ : Ratio of the square of thickness of the enzymatic layer and the reaction length (None)

$\alpha_{1}$ : Dimensionless parameter (None)

$\alpha_{2}$ : Dimensionless parameter (None)

$\delta / L$ : Ratio of the thickness of the enzymatic layer and the thickness of the diffusionconvection layer (None)

F: $\quad$ Faraday constant (None)

$u$ : Normalized concentration of the phenol substrate (None)

$v$ : Normalized concentration of the catechol substrate (None)

$w$ : Normalized concentration of the $o$ quinone product (None)

I: $\quad$ Dimensionless current (None).

\section{Acknowledgments}

This work was supported by the University Grants Commission (F. no. 39-58/2010 (SR)), New Delhi, India. The authors are thankful to Dr. R. Murali, The Principal, The Madura College, Madurai, and Mr. M. S. Meenakshisundaram, The Secretary, Madura College Board, Madurai, for their encouragement. They also thank the reviewers for their valuable comments to improve the quality of the paper. The author K. Indira is very thankful to the Manonmaniam Sundaranar University, Tirunelveli, for allowing to do the research work.

\section{References}

[1] R. Goldman, O. Kedem, and E. Katchalski, "Papain-Collodion membranes. II. Analysis of the kinetic behavior of enzymes immobilized in artificial membranes," Biochemistry, vol. 7, no. 12, pp. 4518-4532, 1968.

[2] P. V. Sundaram and K. J. Laidler, "Kinetic laws for solidsupported enzymes," Canadian Journal of Biochemistry, vol. 48, pp. 1498-1504, 1970.

[3] V. Kasche, H. Lundqvist, R. Bergman, and R. Axen, "A theoretical model describing steady-state catalysis by enzymes immobilized in spherical gel particles. Experimental study of $\alpha$-chymotrypsin-sepharose," Biochemical and Biophysical Research Communications, vol. 45, no. 3, pp. 615-621, 1971.

[4] W. J. Blaedel, T. R. Kissel, and R. C. Boguslaski, "Kinetic behavior of enzymes immobilized in artificial membranes," Analytical Chemistry, vol. 44, no. 12, pp. 2030-2037, 1972.
[5] J. J. Kulys, "The development of new analytical systems based on biocatalysts," Analytical Letters, vol. 14, no. B6, pp. 377397, 1981.

[6] J. J. Kulys, "Development of new analytical systems based on biocatalysers," Enzyme and Microbial Technology, vol. 3, no. 4, pp. 344-352, 1981.

[7] D. A. Gough, J. Y. Lucisano, and P. H. S. Tse, "Twodimensional enzyme electrode sensor for glucose," Analytical Chemistry, vol. 57, no. 12, pp. 2351-2357, 1985.

[8] G. Jobst, I. Moser, and G. Urban, "Numerical simulation of multi-layered enzymatic sensors," Biosensors and Bioelectronics, vol. 11, no. 1-2, pp. 111-117, 1996.

[9] S. Bacha, A. Bergel, and M. Comtat, "Transient response of multilayer electroenzymatic biosensors," Analytical Chemistry, vol. 67, no. 10, pp. 1669-1678, 1995.

[10] S. Bacha, M. Montagné, and A. Bergel, "Modeling mass transfer with enzymatic reaction in electrochemical multilayer microreactors," AIChE Journal, vol. 42, no. 10, pp. 2967-2976, 1996.

[11] R. Baronas, F. Ivanauskas, J. Kulys, and M. Sapagovas, "Hypothesis on the solvability of parabolic equations with nonlocal conditions," Nonlinear Analysis: Modelling and Control, vol. 7, pp. 93-104, 2002.

[12] R. Baronas, F. Ivanauskas, J. Kulys, and M. Sapagovas, "Modelling of amperometric biosensors with rough surface of the enzyme membrane," Journal of Mathematical Chemistry, vol. 34, no. 3-4, pp. 227-242, 2003.

[13] R. Baronas, F. Ivanauskas, and J. Kulys, "The influence of the enzyme membrane thickness on the response of amperometric biosensors," Sensors, vol. 3, no. 7, pp. 248-262, 2003.

[14] R. Baronas, F. Ivanauskas, J. Kulys, and M. Sapagovas, "Modelling of amperometric biosensors with rough surface of the enzyme membrane," Journal of Mathematical Chemistry, vol. 34, no. 3-4, pp. 227-242, 2003.

[15] L. Coche-Guerente, P. Labbé, and V. Mengeaud, "Amplification of amperometric biosensor responses by electrochemical substrate recycling. 3. Theoretical and experimental study of the phenol-polyphenol oxidase system immobilized in laponite hydrogels and layer-by-layer self-assembled structures," Analytical Chemistry, vol. 73, no. 14, pp. 3206-3218, 2001.

[16] C. D. Mell and J. T. Maloy, "A model for the amperometric enzyme electrode obtained through digital simulation and applied to the immobilized glucose oxidase system," Analytical Chemistry, vol. 47, no. 2, pp. 299-307, 1975.

[17] C. D. Mell and J. T. Maloy, "Amperometric response enhancement of the immobilized glucose oxidase enzyme electrode," Analytical Chemistry, vol. 48, no. 11, pp. 1597-1601, 1976.

[18] J. J. Kulys, V. V. Sorochinskii, and R. A. Vidziunaite, "Transient response of bienzyme electrodes," Biosensors, vol. 2, no. 3, pp. 135-146, 1986.

[19] T. Schulmeister, "Mathematical modelling of the dynamic behaviour of amperometric enzyme electrodes," Selective Electrode Reviews, vol. 12, no. 2, pp. 203-260, 1990.

[20] V. V. Sorochinskii and B. I. Kurganov, "Steady-state kinetics of cyclic conversions of substrate in amperometric bienzyme sensors," Biosensors and Bioelectronics, vol. 11, no. 3, pp. 225238, 1996.

[21] K. Yokoyama and Y. Kayanuma, "Cyclic voltammetric simulation for electrochemically mediated enzyme reaction and determination of enzyme kinetic constants," Analytical Chemistry, vol. 70, no. 16, pp. 3368-3376, 1998. 
[22] R. Baronas, F. Ivanauskas, and J. Kulys, "Modelling a biosensor based on the heterogeneous microreactor," Journal of Mathematical Chemistry, vol. 25, no. 2-3, pp. 245-252, 1999.

[23] W. E. Ames, Numerical Methods for Partial Differential Equations, Academic Press, New York, NY, USA, 2nd edition, 1977.

[24] L. Coche-Guérente, V. Desprez, J. P. Diard, and P. Labbé, "Amplification of amperometric biosensor responses by electrochemical substrate recycling. Part I. Theoretical treatment of the catechol-polyphenol oxidase system," Journal of Electroanalytical Chemistry, vol. 470, no. 1, pp. 53-60, 1999.

[25] L. Coche-Guérente, V. Desprez, P. Labbé, and S. Therias, "Amplification of amperometric biosensor responses by electrochemical substrate recycling. Part II. Experimental study of the catechol-polyphenol oxidase system immobilized in a laponite clay matrix," Journal of Electroanalytical Chemistry, vol. 470, no. 1, pp. 61-69, 1999.

[26] R. Baronas, J. Kulys, and F. Ivanauskas, "Mathematical model of the biosensors acting in a trigger mode," Sensors, vol. 4, no. 4, pp. 20-36, 2004.

[27] J. H. He, "Some asymptotic methods for strongly nonlinear equations," International Journal of Modern Physics B, vol. 20, no. 10, pp. 1141-1199, 2006. 


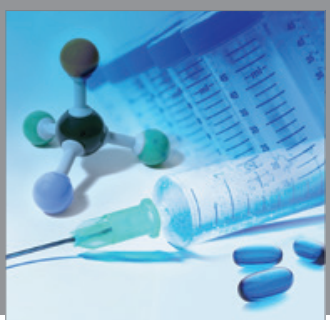

International Journal of

Medicinal Chemistry

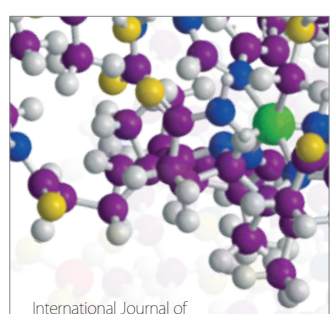

Carbohydrate Chemistry

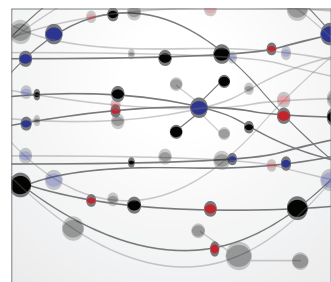

The Scientific World Journal
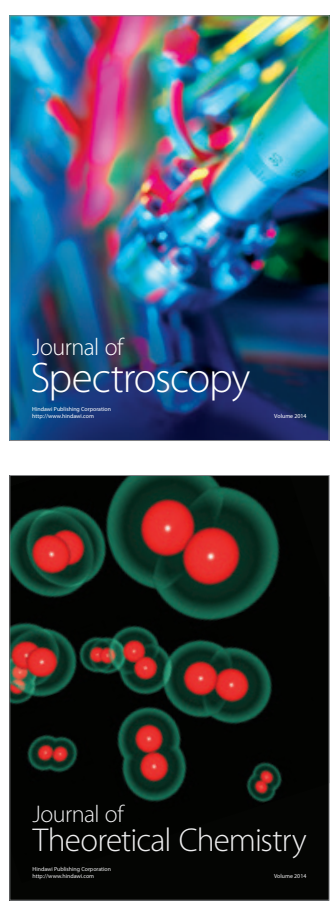
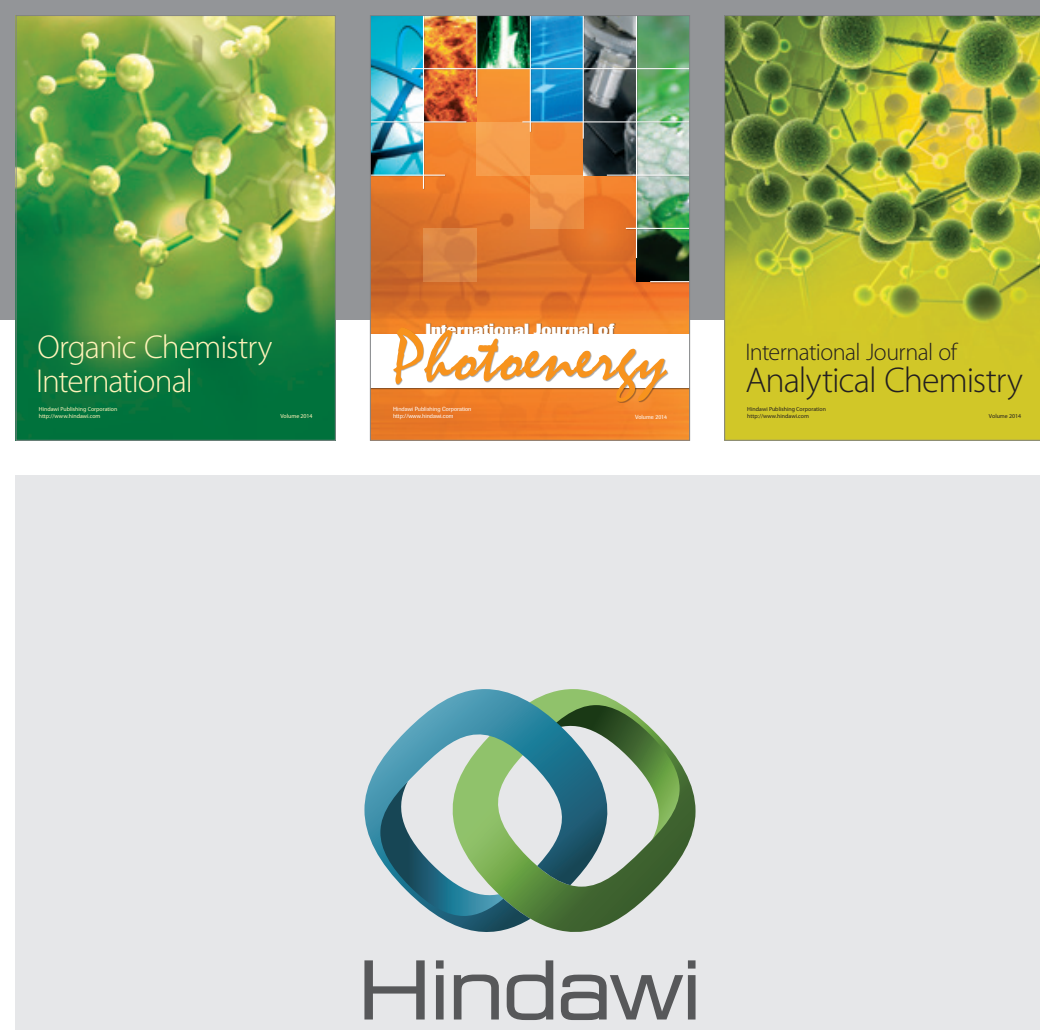

Submit your manuscripts at

http://www.hindawi.com
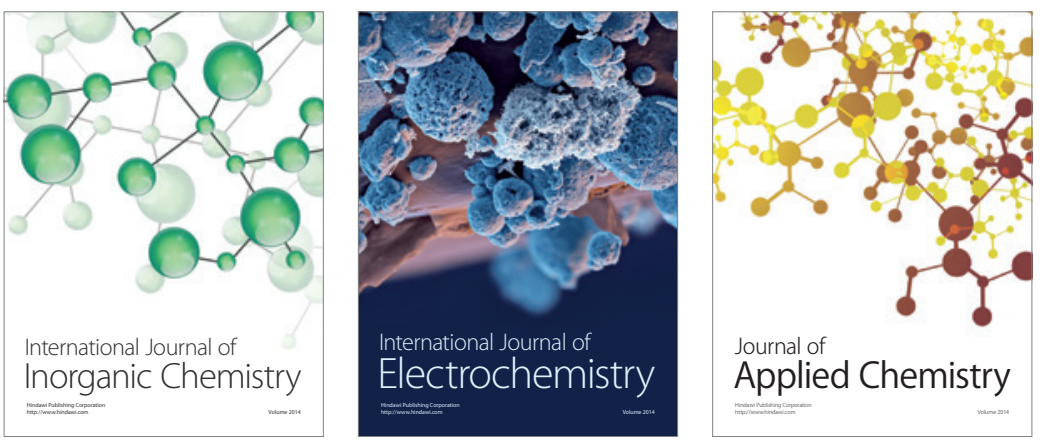

Journal of

Applied Chemistry
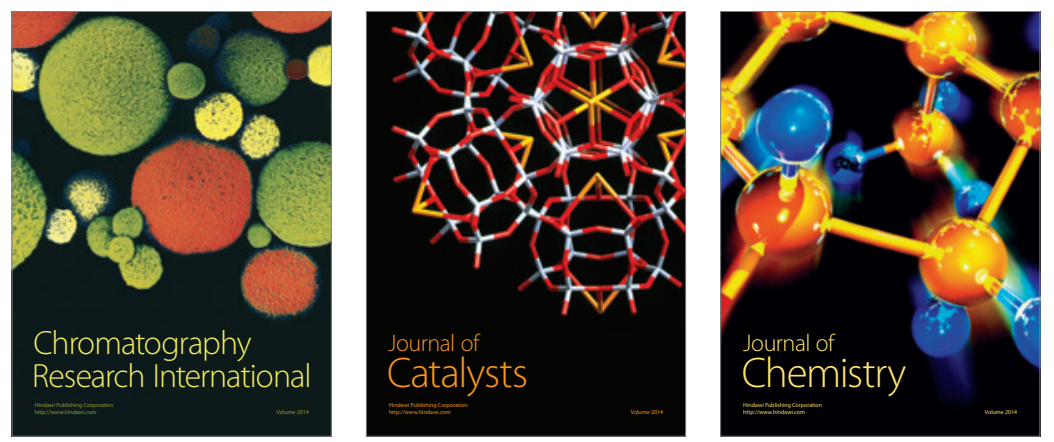
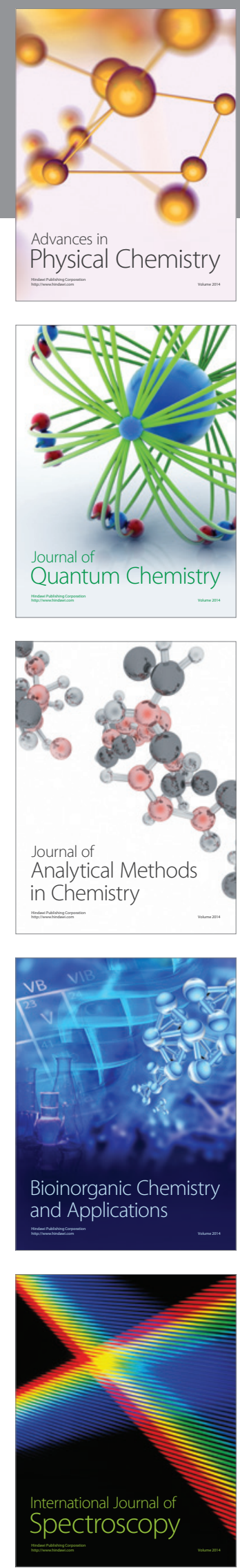